\title{
Organization and recall of pictures and words in children*
}

\author{
ARNOLD POWELL, JAMES HAVNAER, and WENDALL WIGGINS \\ Columbus College, Columbus, Ga. 31907
}

Recall and category clustering of pictures and words were investigated among Ss from the third, fourth, and sixth grades. Both recall and organization were greater among older Ss and for pictorial stimuli. Recall was correlated with scores on a standardized achievement test designed to measure paragraph comprehension ( $\mathrm{PC}$ ). The $\mathrm{Z}$-score measure of clustering was found to yield more reliable and consistent results than the adjusted ratio of clustering. Some of the change in recall as a function of age was associated with both category clustering and PC scores. This finding was interpreted as supporting the view that memory does not develop as an isolated skill, but reflects the child's developing ability to transform surface structures into abstractly organized deep structures. It was suggested that pictures are easier to recall because the transformation of surface structure representations into organized deep structures is less influenced by the context of encoding than it is in the case of words.

Several recent studies of the development of free recall learning in children (e.g., Cole, Frankel. \& Sharp. 1971: Neimark, Slotnick, \& U'lrich, 1971 ) have consistently found that the number of items recalled increases as a function of age. Since organizational processes are important in the storage and retrieval of information from long-term memory (Bower. 1970), attempts have been made to relate these changes in recall as a function of age to changes in organizational processes. It has been found that subjective organizaticn and category clustering do increase with age and that these increases can account for at least some of the increase in recall (e.g., Cole et al: Neimark et al). Neimark et al found that the amount of time spent in recall decreased with age, which, in combination with other findings. suggested that older Ss have better organizational strategies and, thus, are better able to keep track of what has been recalled and what is left that can be recalled. Age-related changes in serial position curves (Cole et al) also implicate the role of organizational processes. There is a tendency for serial position curves to become progressively flatter among older Ss, with the number of items recalled increasing for the initial and middle items but not for the last few items. The items appearing last during input tend to be recalled from short-term store, while the initial items tend to be organized, stored, and

* The authors would like to express their appreciation to the teachers and pupils at Muscogee Elementar School in Columbus. Ga., and to Earl Carr for his assistance in conducting this investigation. Requests for reprints mav be sent to Arnold Powell. Department of Psychology, Columbus College. Columbus. Ga. 31907. retrieved from long-term store (Glanzer \& Cunitz, 1966; Powell \& Weist, 1971).

There are a variety of potential variables that could account for age-related changes in recall. At a simple level, for example, word knowledge should be important; increasing experience with a particular lexical item should facilitate its location and retrieval from long-term memory. On the other hand, general cognitive processes that develop during childhood and which enable the translation of surface structures into abstractly organized deep-structure representations should also be important in recall and the general development of memory. Neimark et al (1971) and Neimark \& Slotnick (1971) have implicated the importance of such processes in their proposal that the development of memory skills represents an aspect of more general cognitive development.

The child's ability to transform surface structures into abstract deep structures is measured to some extent by tests of paragraph comprehension. Such tests require $S$ to read meaningful prose and then answer a series of questions designed to test his general comprehension of the underlying ideas. Performance on paragraph comprehension tests requires complex cognitive processes and does increase as a function of age. Therefore, it was hypothesized that paragraph comprehension scores would be correlated with recall, and that at least some of the variance in recall across ages would be associated with such scores. The present study was designed to test this hypothesis and to investigate the relation of general word knowledge and stimulus modality (i.e., pictures vs words) to age-related changes in recall.
METHOD

Subjects

The Ss were 24 males and 24 femaies enrolled in a local elementary school; 8 males and 8 females were selected from the third. fourth, and sixth grades. Grade level equivalents on the word knowledge and paragraph comprehension subtests of the Comprehensive Tests of Basic Skills and Otis-Lennon IQs were obtained from the permanent records of the tests administered at the beginning of the school year. ${ }^{1}$ The experiment was conducted shortly after the middle of the school year. All Ss were reading on at least a third grade level and the mean IQ was $108(\mathrm{SD}=11.2)$.

Stimulus Material

The to-be-remembered items were 16 high-frequency concrete nouns, + items each from four taxonomic categories. The actual items were: camel, elephant, alligator, lion. bicycle, car, truck, ship, socks, coat, pants, hat, hand, ear, foot, and eye. Pictures of the items were simple line drawings taken from several children's tests of mental ability. The pictures and words were mounted separately on individual $35-\mathrm{mm}$ slides. Three random orders of the items were constructed, using a table of random numbers.

\section{Procedure}

After free recall instructions had been read, three practice items were presented in order to familiarize Ss with the procedure. Once it was clear that all Ss understood the task, four free recall trials were presented. Items were presented at a $2.5 \cdot \mathrm{sec}$ rate on a Lehigh Valley programmable slide projector with an external timing device. Three minutes were provided for recall on each trial. The order of presentation was the same on Trials 1 and 4 . The Ss were tested in groups of eight, and recall was written.

The Ss trom each grade level were assigned randomly to either a picture (Group P) or a word (Group W) group. the only qualification being that there be an equal number of males and females in each condition. Group $P$ was instructed to remember the names of the pictures, and Group If was instructed to remember the words. Recall protocols were scored for number of words recalled on each trial and for category clustering, using both the adjusted ratio of clustering (ARC: Roenker, Thompson, \& Brown, 1971) and the Z-score clustering measure (Frankel \& Cole, 1971).

\section{RESLLTS}

Nean numbers of items recalled on all four trials at each grade level for Groups $\mathrm{P}$ and $\mathbb{W}$, separately, are shown in the top portion of Fig. 1. As can be seen, recall increased as a function of grade level; the function was 

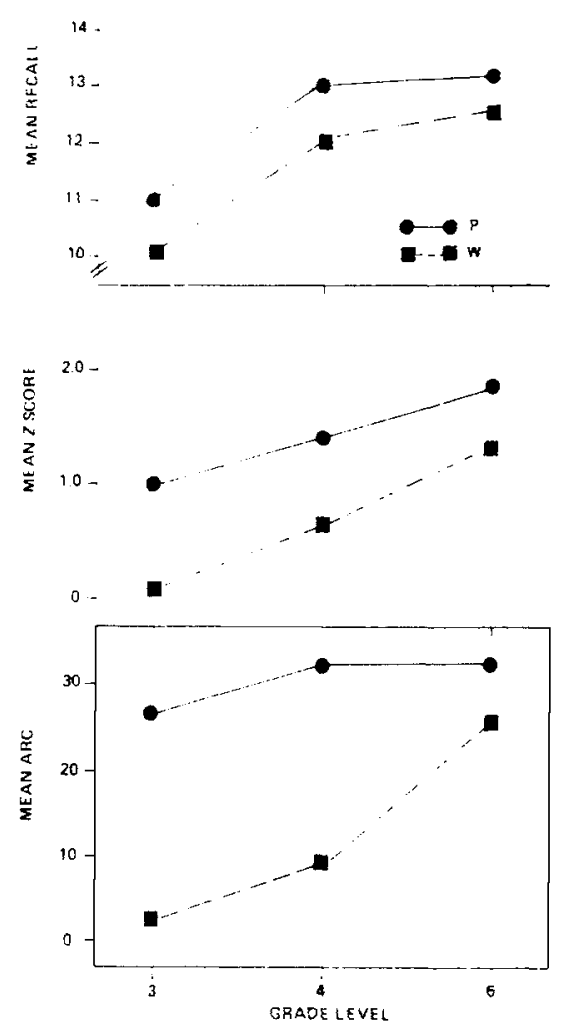

Fig. 1, Mean recall, $Z$ scores, and ARC as a function of grade for pictures (P) and words (W).

nonlinear, with the largest difference occurring between the third and fourth grades and only a slight difference between the fourth and sixth grade levels. Group $P$ recalled more items than did Group W, the difference being nearly constant across grades. The reliability of these results was evaluated in split-plot analysis of variance (Kirk, 1968). The effects of grade level $(F=9.32, \mathrm{df}=2 / 42$, $\mathrm{p}<.01)$ and trials $(\mathrm{F}=20.33$, $\mathrm{df}=$ $3 / 126, p<.001$ ) were significant. The effect of stimuli approached significance $(\mathrm{F}=3.41, \mathrm{df}=1 / 42$, $p<.10$ ). None of the interactions was significant.

Mean ARC and $Z$, for each grade level and for Groups $P$ and $W$, are shown in the bottom two panels of Fig. 1. Even though there was a very high correlation between ARC and $Z$ scores $(r=.87, \mathrm{df}=46, \mathrm{p}<.001)$, the pattern of the results was slightly different for these two measures of clustering, as it was in the study by Cole et al. While ARC was consistently higher for Group P than for Group W, there was little evidence for change as a function of grade level; mean $\mathrm{Z}$ was also higher for Group $\mathrm{P}$ and did vary as a function of grade level. With ARC, the significant effects were stimuli ( $F$ $7.23, \mathrm{~d} f=1 / 42, \mathrm{p}<.025)$, trials $(F$ $=2.65, \mathrm{df}=3 / 126, \mathrm{p}<.05)$, and the Grade by Stimuli by Trials interaction $(F=2.60, \mathrm{~d} f=6 / 126, p<.05)$, which was uninterpretable. The effects of grade and of the Grade by Stimuli, Grade by Trials, and Stimuli by Trials interactions were nonsignificant. In the case of $Z$, the effects of grade $(F=$ $3.62, \mathrm{df}=2 / 42, \mathrm{p}<.05)$, stimuli $(\mathrm{F}=$ 5.70 , df $=1 / 42, p<.025)$, and trials $(F=6.11, \mathrm{df}=3 / 126, \mathrm{p}<.001)$ were all significant; none of the interactions was significant. The between Ss' error mean square was used as an estimate of the population variance of $\mathrm{Z}$ in the computation of $t$ and, with the exception of Group $W$ at the third and fourth grade ievels, all group means were significantly different from chance-level clustering.

It should be noted that the results of the Z-score clustering analysis differ slightly from those reported in Cole et al (1971), in which third and sixth graders were also compared. In general, there was less clustering on the part of Ss in the present study, and there was no evidence for a Grade by Trials interaction. Cole et al used 20-item lists and 90-sec recall periods, but it is not known whether these procedural differences can account for the difference in the results.

The mean paragraph comprehension (PC) scores for the third, fourth, and sixth grades were, respectively, 3.8 $(\mathrm{SD}=1.0), 4.5(\mathrm{~S} D=.99)$, and 6.9 $(S D=1.37)$; the mean word knowledge (WK) scores were, respectively, $3.8(\mathrm{SD}=.87), 4.5(\mathrm{SD}=$ $.92)$, and $6.9(\mathrm{SD}=1.64)$. $\mathrm{PC}$ scores correlated more highly with recall $(\mathbf{r}=$ $.44, \mathrm{df}=45, \mathrm{p}<.01$ ) than $\operatorname{did} \mathrm{WK}$ scores $(r=.34, \mathrm{df}=45, \mathrm{p}<.05)$. While there was a very high correlation between PC and WK scores $(r=.89)$, this difference was small and only approached significance $(t=1.66, d f=$ $44, p<.10)$. Although some of the change in recall over grade level is associated with changes in PC scores, there is still a significant grade effect when differences are statistically held constant $[F($ adj $]=4.80, \mathrm{df}=2 / 41$, p $<.05]$

Mean clustering scores were also correlated $^{2}$ with recall $(r=.36, d f=38$, $\mathrm{p}<.025$ ). Since $\mathrm{PC}$ and $\mathrm{Z}$ scores were relatively independent $(\mathrm{r}=.17)$ and both were correlated with recall, the combination of the two provides an even better prediction of recall (multiple $\mathrm{R}=.51, \mathrm{df}=38, \mathrm{p}<.01$ ). This relationship was slightly higher for Group $\mathrm{P}(\mathrm{R}=.60)$ than for Group $W(R=.42)$, but the difference was not significant.

It should be noted that none of the above results is confounded by the effects of intelligence, since IQ failed to correlate with either recall $r=.13$ ) or clustering $(\mathrm{r}=-.05)$.

\section{DISCUSSION}

The results supported the hypotheses and corroborate the findings of other recent investigations of the development of free recall learning. At least some of the increase in recall that occurs as a function of $\mathrm{CA}$ can be attributed to changes in organizational processes. The results also support the view of Neimark et al (1971) that developmental changes in recall reflect more general cognitive development, since the ability to comprehend meaningful prose was correlated with recall. The results suggest that this relationship cannot be attributed to simple word knowledge or to the tendency to use taxonomic categories as retrieval schema. As development progresses, there is an increasing ability to translate surface structures into abstractly organized deep-structure representations. This process is distinct from-though certainly related to-the tendency to build storage and retrieval schema around taxonomic categories. This view of memory and cognitive development is congruent with those models of memory that distinguish between rehearsal as simple repetition and rehearsal as a reconstructive process (Neisser, 1967; Weist, 1972). According to the reconstructive model of rehearsal, it involves the transformation of information in working memory into integrated cognitive units according to S-generated rules.

The finding that recall and clustering are higher for pictures than for words, and that the difference remains nearly constant across different age groups, has been replicated in numerous studies (cf. Paivio, 1971). Paivio has emphasized the role of imagery and concreteness in the explanation of this finding. However, greater attention should be given to the role of organization and reconstructive processes. The pictorial stimuli typically used in free recall studies seem to index relatively less ambiguous cognitive events than their verbal labels. The recall and organization of even highly concrete (and high category frequency) nouns are sirongly influenced by the context in which they are encoded (Weist \& Powell, 1972). It seems possible, then, that there are more alternatives involved when transforming the surface structure of words into underlying deep structure than in the case of pictorial stimuli. If so, the recall and organization of pictorial stimuli should be less influenced by the context of encoding.

Two recent measures of clustering were found to be highly correlated 
with one another. Howerer, the Z-score clustering measure (Frankel \& Cole, 1971) yielded results that are more easily interpreted and are more consistent with previous results than did the ARC measure (Roenker et al, 1971). This supports Frankel and Cole's contention that the former provides a more useful measure of clustering.

It is interesting to note that IQ failed to correlate with either recall or clustering. This raises questions concerning the possible relationship between $11 \mathrm{~A}$ and organization processes in recall and should be investigated further.

\section{REFERENCES}

BOWER, G. H. Organization factors in memory. Cognitive Psychology, 1970. 1. $18-46$.

COLE, iI. FRANKEL. F.. \& SHARP. D.
Deselopment $" 1$ fret retall lea"ming in children. Developmental Psichology. $1971,4.109-123$

FRANKEL. F.. \& COLE. M. Measure of organization in free recall. Psychological Bulletin, $1971,76,39-44$.

GLANZER, M.. \& CUNITZ. A. R, Two storage mechanisms in free recall. Journel of Verbal Learning \& Verbal Behavor. 1966.5.51-360

KIRK, R F, Experimental design Procedures for the behatioral sciences. Belmont. Calif: Brooks/Cole, 1968

NEIM.ARK. E. D., \& SLOTNICK, N. S. Spontantous imposition of organization: A developmental study. Paper presented at the meeting of the Eastern Psichological Assoctation. Atlantic City. April 1970

NEIMIARK. E. D.. \& SLOTNICK. N. S., \& ULRICH, T. Development of memorization stiategies. Developmental Psychology, 1971,5.427-432.

NEISSER, C, Cognitive psichology. New York: Appleton-Centur-Crufts, 1967.

PAIVIO, A. Imagery and lerbal processes. New York: Holt, Rinehart, \& Winston. 1971

POWELL.A.. \& WEIST. R. M. Blocking and ambiguous wores in multatid fres recall. Paper presented at the meetum of the Rocky Ilountain Psychologied Associdtion. Denver. Nay 1971.

ROENKER, D. I.. THONPSON, C. A.. \& BROWN. S. C. A comparison of measures for estimation of clustering in free recall. Psvchological Bulltin, 1971, 76, 45-48.

WE.IST, R. M. The role of rehearsal: $R+c o p v$ or reconstruct. Journal of Verbal Learning \& Verbal Behavior, 1972. 11. 440-450.

HEIST. R. M.. \& POWELL, A. Blocking in multitria! foe recall. Journal of Experimental Psychology. 1972. 93. $298-403$.

$$
\text { NOTES }
$$

1. Scries were not avalable for one $S$ in the sixth grade group.

2. Correlation data are reported for $Z$ scores onlv, since the difterences between $A R C$ and $Z$ were negligible and nonsignificant. Eight $S$ s had average clustering scores that were beluw chance and, therefore, their data were not included in the following analuses. The following analyses were conducted for the entire sample, but the differences were negligible and nonsignificant. 